International Journal of Child, Youth and Family Studies (2012) 2 \& 3: 214-233

\title{
TELL IT LIKE YOU SEE IT: YOUTH PERCEPTIONS OF CHILD AND YOUTH CARE PRACTITIONER INTERVENTIONS AND OUTCOMES IN AN ALTERNATIVE SCHOOL SETTING
}

\author{
Cait McMillan, Carol Stuart, and Jennifer Vincent
}

\begin{abstract}
Using a semi-structured interview format, students $(n=7)$ attending an alternative school program who were supported by child and youth care (CYC) practitioners described their view of the work these practitioners do and the effect it has on the students. We were interested in learning about how students perceived the strategies and interventions they experienced and how the said interventions affected student outcomes. Students described program strategies such as the use of a token economy and daily group sessions as well as practitioner strategies including presence, support, use of self, and the student as resources for information and assessment. Students accomplished a variety of academic and socio-emotional outcomes, and identified the relationship as the basis for effective work between themselves and the CYC practitioner. Students identified both passive and persistent engagement strategies in the relational context. Together, these two types of engagement seem to create a continuum of constant engagement. Through a comparison of the student perceptions to the CYC practice literature, we offer a beginning point for a dialogue between students and theorists and researchers about some of the accepted and common practice strategies in our field.
\end{abstract}

Keywords: school-based practice, interventions, outcomes, youth perspective

Cait McMillan, B.A. is a certified CYC practitioner working with youth in a residential setting in Ottawa, Ontario, Canada. E-mail: cait.mcmillan@gmail.ca

Carol Stuart, Ph.D. is the Dean of Health and Human Services at Vancouver Island University, 900 5th Street, Nanaimo, British Columbia, Canada, V9R 5S5.

E-mail: carol.stuart@viu.ca

Jennifer Vincent, B.A. is a Master's student in the School of Child and Youth Care at the University of Victoria, P.O. Box 1700, STN CSC, Victoria B.C., Canada, V8W 2 Y2. E-mail: vincent4@uvic.ca 
Increased pressure on the part of government for accountability has led service providers in children's mental health to adopt Evidence-Based Practice (EBP), train child and youth care counsellors in specific Evidence-Based Treatments (EBT), and focus on gathering outcome data for children, youth, and families who use their services. As such, there is a growing interest in further understanding the way that CYC counsellors are developing and utilizing specific EBP/T activities within the life space of clients and in formal intervention protocols. The uptake of $\mathrm{EBP} / \mathrm{T}$ in children's mental health has influenced other service sectors employing CYC practitioners, including child welfare, juvenile justice, and, to a lesser extent, the education sector.

Previous research on the use of EBP/Ts (Stuart, Fulton, Kroll, Rapuano, \& McMillan, 2008) showed that CYC practitioners working in group care settings implement many different intervention strategies that are consistent with intervention strategies used in EBP. These practitioners apply the interventions in the life space of the young person in planned and purposeful ways that are consistent with treatment goals. Although evidence-based practices are frequently used by CYC practitioners in group care, there has been limited exploration of the EBP used in non-residential settings or the specific outcomes that derive from CYC interventions. Research on the working strategies of CYC practitioners which precipitate outcomes for young people has relied primarily on the scientific approach through the implementation of EBP/Ts. It is understood in practice that across settings the intervention strategies of CYC practitioners include, but also reach far beyond, the utilization of EBP/Ts. Relationship, for example, is a mechanism for change which cannot be captured in a scientific approach. A CYC approach to working with young people seeks their meaningful engagement and values their voices as evidence regarding what interventions and strategies are helpful to them and the relation of the interventions to outcomes. Engaging youth by soliciting their opinions about the intervention activities and resultant outcomes is a crucial aspect of gathering new information about what is of value to those served.

Given the significant lack of current research that addresses what types of strategies CYC practitioners employ in the educational sector, we were interested in speaking with young people about their experiences with CYC practitioners in a school setting. The goal of this study was to explore the relationships between life space intervention strategies of CYC practitioners, the service program(s), and the outcomes of the participating youth in an alternative school setting. Our specific research objectives were:

1. to understand how students perceived the intervention strategies they experience in a school setting; and

2. to identify how students connected interventions with their real or anticipated outcomes.

\section{Method}

The research reported here is part of a larger study exploring perceptions about CYC strategies for intervention and the resultant outcomes of both CYC practitioners and the youth 
International Journal of Child, Youth and Family Studies (2012) 2 \& 3: 214-233

they work with. Social service organizations that engaged CYC practitioners to provide a variety of services to youth volunteered to participate. An exploratory qualitative approach using semistructured interviews enabled us to engage youth in a discussion about their perceptions of the work of CYC practitioners. The interview questions were designed to elicit information about the perceptions of the strategies and interventions used and the outcomes experienced by the youth. The semi-structured interview approach provided opportunity for the participants to speak freely in their own words, and flexibility for researchers to probe participants to clarify or request further detail.

\section{Setting}

All participants attended an alternative high school program (Section 23) in the Toronto area. Students attended the program because they had been identified (by self or other) as requiring extra academic and socio-emotional supports not available to them in a mainstream school setting. The program was located in a building that was shared with another (unassociated) school, each with their own entrances and schedules. The program employed four teachers and four CYC practitioners with a maximum of 24 high school students.

\section{Recruitment and Data Collection}

Using a purposeful approach to recruitment, CYC practitioners in the school provided preliminary information on the study to students whom they felt were experiencing success and who could speak to their experiences within the setting. We then met with the students as a group at the school to provide additional details on the study and emphasize the voluntary nature of participation. Written informed consent was obtained from participants during this meeting and interviews were scheduled for the time immediately following the meeting in a room separate from the classroom area. A team of three researchers individually interviewed the students. In total, seven $(n=7)$ students participated, five males and two females, aged 16 to 18 years. Two had been in the program less than 6 months, four between 6 and 12 months, and one had been in the program for over one academic year. The interviews were audiotaped and lasted an average of 30 to 40 minutes. Students received a \$25 honorarium for their participation in the study.

\section{Data Analysis}

Interviews were transcribed verbatim in preparation for analysis. All identifying information in the data was replaced with a participant code in the process of transcription. The interviews were coded thematically using NVivo 8 software. Preliminary analysis consisted of a line-by-line review of the data without any preconceived ideas to identify preliminary themes. Once preliminary themes were identified, they were reviewed with the second author following her independent review of the transcripts. The discussion of preliminary themes grounded the themes in the data and identified overarching themes related to the research questions. The analysis was initiated by the first author and checked independently and collaboratively with the 
International Journal of Child, Youth and Family Studies (2012) 2 \& 3: 214-233

second author through regular meetings to review the emerging themes ${ }^{1}$. After each meeting the first author returned to the data to check and code new emergent themes and revise the analysis.

\section{Results}

Six separate but interconnected themes emerged in thematic analysis:

1. CYC practitioners inserting themselves in the life space.

2. Program strategies of CYC practitioners, which includes sub-themes of the token economy and group time.

3. Working strategies of CYC practitioners, which includes sub-themes of presence, support, use of self, students as a resource, and assessment.

4. Student perspectives on treatment goals.

5. Student perspectives on outcomes now and in the future, which includes sub-themes of future outcomes, academic outcomes, and socio-emotional outcomes.

6. Relationship, which includes sub-themes of development of relationship, naming the relationship, relating strategies to outcomes, passive engagement and persistent engagement. The sub-themes passive engagement and persistent engagement were strategies used by CYC practitioners in the relational context, which together formed a continuum of constant engagement.

\section{CYC Practitioners Inserting Themselves in the L ife Space}

CYC practitioners engaged with students primarily in the school environment; however, youth $(n=6)$ described instances in which their practitioners connected the school and the home spaces through regular communication. In the eyes of students, this constant contact between CYC practitioners and youths' caretakers promoted their success.

Constant contact with the guardians. Which I don't know how awesome that is for the kids themselves, but ... when everyone knows everything, well that may not be what a lot of people want or desire, it is definitely something that is helpful because there is constant contact and support in between the two. (002cs)

The student further described this "constant contact” as a way for the CYC practitioners to make their presence known to the youth outside of the school environment. The extension of practice beyond the "place" of school and into a more broadly defined life space was noted by another student who identified how she transferred her newly acquired social skills to other systems in which she was involved. Neither the practice strategies nor the outcomes were restricted to the school setting.

1 The third author interviewed students for this study and completed an analysis of data from CYC practitioners in the program. 
International Journal of Child, Youth and Family Studies (2012) 2 \& 3: 214-233

\section{Program Strategies of CYC Practitioners}

Program strategies were used by all CYC practitioners and affected all students in the school. Participants identified rules, routines, rewards, and group activities as important contributors to their success at the school. Built into the school program were daily routines and rules established as structures for the students.

But sometimes their parents can't afford certain things or say for instance can't make a lunch every day. So what happens here is the program here has lunches on Mondays and Fridays where you make a sandwich, or make a sandwich and have a pop or something like that...And certain days of the week we have hot lunch. That means, like last Monday, I actually made spaghetti and meatballs. (001)

Sometimes you have to owe back time if you're late and stuff, but I think that reassures me that I need not to be late so that, you know, at least there is some type of discipline here. (003jv)

Rewards for good behaviour included early dismissal, extra breaks, computer time, and earning dollars towards the token economy. The token economy was a structure that the CYC practitioners used to reward students when they noticed positive behaviours or "good" choices on the part of the students. In addition to program-wide rewards available to all students, youth were able to earn "dollars" by demonstrating behaviours related to their individual case plans and goals. Students believed that the presence of the reward system called "D dollars" kept them motivated to be on time and on task throughout the day, while helping them develop a sense of responsibility to themselves and others.

Oh yeah, we have - we have, we also have auction. Which is like for everything we do good, for instance I get - basically it's D dollars, right. So if we do - if we do good class, like if we do good in class like no interruptions, get down to work, you just got yourself five D dollars. And every two weeks you auction - they put stuff up for auction. Like for instance, um - this, say this was five D dollars, and then the bid would start at five, and like five dollars - six, seven, eight ... and you can earn gift cards, McDonald's or Tim Hortons or HMV, or Wal-Mart, or anything. We usually, sometimes we get candy, pop, chips, you know, you name it...one time somebody won an MP3 player. So yeah, it was pretty good. (001)

All students participated in a daily group session developed and led by CYC practitioners. Group was an interactive environment where students learned social and other life skills. As described below, the topics varied and seemed to be jointly determined between students and CYC practitioners.

We've done stuff on safe sex, a thing we were doing on nutrition; we just recently watched The Pianist and discussed it and all that. So it's a smattering of everything. Just on stuff that the staff thinks are interesting and can help us in our current time in life. (002cs) 
International Journal of Child, Youth and Family Studies (2012) 2 \& 3: 214-233

\section{Working Strategies of CYC Practitioners}

The students ( $n=7$ ) identified a variety of planned and in-the-moment strategies that were employed by the CYC practitioner, the youth, or through collaborative efforts by both players. They included presence, support, the use of self, the student as a resource for information, and assessment.

Presence. Students noted that the ongoing, non-intrusive presence of CYC practitioners in their physical life space allowed practitioners to observe and assess needs so that they could then help students manage and respond to emotional states. Here, a student identified a situation where the CYC practitioner acted after she had been present over a period of time:

Like, we have this thing called Group where we all, sometimes we all sit and talk. I used to sit in the back and I didn't say anything. Then she would call me out, and before I got really mad, but I realized that it was actually helping me, because I needed that push to talk more. $(003 \mathrm{~cm})$

The constant presence of the CYC practitioners in the school allowed students to call upon the workers when they needed support or guidance:

I'd have to say, you know, I just would miss the constant presence, because it's like they're always there. Even if I'm not using it, I could go say "I'm having a problem with this. I need help with this. Can you help me?” And that's always really great and just the constant - their presence here and how they're just so great with everyone. (002cs)

Support. The CYC practitioners’ physical presence in the life space created an environment that prepared students to receive and/or seek out support. Support was provided for both academic and socio-emotional reasons. All students $(n=7)$ noted that their primary CYC practitioner actively engaged in providing them with one or both of these types of support: "For the most part they are there to support you academically and also - like, I don't know what the word is, not mentally, but like more emotionally” (003jv).

Students described both active and conversational support. CYC practitioners engaged in active support with students by providing specific assistance to accomplish goal-related tasks or to help them advocate for themselves. Conversational support involved verbal response to a behaviour, validation, congratulations, advice or guidance, and motivation. Active listening by the CYC practitioner was a key component of student support. Students indicated that both types of support provided them with tools and created opportunities that allowed them to take risks and experience new things. The positive reinforcement that one student received from the CYC practitioners was a strong motivating factor that encouraged her to work toward her goals. She compared her experiences in the program to those she had in mainstream schools: "It's like nobody ever notices. But to me, here, it's more the attention that you get, it's more reassuring" (003jv). 
Students compared the support systems in the school to those found in families. Here, the student explained that the support that he received from his primary CYC practitioner was much like the support that he would expect from a mother, who reminds him of daily events and tasks and assists him with developing proper social interactions with others. He said that the personal and tight-knit environment the staff created in the school felt much like a family:

It's a very personal setting, it's like a family-like setting, because we are together all day, everyday. So it's really great to be in the setting, because some students here are in residence, group homes, where they may not get that kind of family setting where they should be. So it's good that they can come to this school, this program, where they can get that kind of family setting. Because we do come here, we do work, we have fun, play games, we um - we had a Thanksgiving dinner, we had a Christmas dinner here, we had a Hallowe'en party, we had all these little get-togethers, all these little lunches, it's really good. Yeah. (002jv)

Use of self. Students described how CYC practitioners used themselves as tools in their personal approach to practice, using their personality and interests to inform how they interacted with students. Areas of common interest between CYC practitioners and students, such as movies, music, and sports, formed the basis of conversations at breaks, at lunch, or in the morning before school. Students reacted differently to the varied ways that CYC practitioners engaged them, and invested more in the topics and individuals who most suited their personal interests:

So like, it's great, because I can relate to her. Like, we listen to the same kinds of music, some of the same interests and whatnot. So it's easy to sit down and talk to her, not like youth worker and student, but like acquaintances. (002jv)

Overall, students ( $n=6)$ appreciated the ways that CYC practitioners informed practice using self, and were approachable when advice, companionship, or support was sought.

I think she just is a very approachable kind of person. She's really down to Earth, so it's really easy to go up to her and say, you know, "I'm having a problem with this so on and so forth, could you help me?” And she doesn’t like, you know, when you're in class we'll talk at break or talk at lunch - she's like, okay. We'll sit down and we'll talk about the issue at hand and maybe brainstorm some ideas as to what we can do and we'll go from there. So she's - she's just been amazing all year. (002jv)

Students as a resource. Students are resources for information about their own needs and their progress made in the program. CYC practitioners asked students to share how intervention strategies were working, and to identify where they thought the approach should be changed to increase their opportunities for success. Their responses allowed CYC practitioners to gather information and collaboratively develop new working approaches.

A ssessment. Students identified the formal and informal assessments used to determine academic and socio-emotional needs and goals, and to track their progress over time. Informal assessments happened frequently (daily or weekly according to youth needs) through 
International Journal of Child, Youth and Family Studies (2012) 2 \& 3: 214-233

conversation initiated by either a practitioner or the student. They were generally unplanned, but students observed that assessment was a significant part of the CYC practitioners' regular routine. Formal assessments were performed during regular case plan meetings with primary workers where students shared their successes and struggles and updated their case plans. These assessments were individualized and personalized to fit each youth, and were not limited to formal program goals but could include any part of the life space that was relevant. Case plan meetings were scheduled on a biweekly to a monthly basis.

Students further noted that CYC practitioners also assessed the quality and effectiveness of interventions with students by asking questions and making observations. CYC practitioners asked students whether or not particular strategies and interventions were helpful to them, and students became comfortable approaching their primary CYC practitioner if there was an intervention or a strategy being employed that was not a good fit for them.

Because she asks, like, “Did you accomplish this today?” and I tell her yes or no. And if it doesn't [work], she'll say "Okay, we'll try something else, or we'll see what needs improvement”. And if it does, she’s happy. Yeah, but if it doesn't, then she usually helps me on what didn't, what went wrong in it, or how come, what stopped me from completing it. Then we'll work on that. $(003 \mathrm{~cm})$

\section{Student Perspectives on Treatment Goals}

Students identified goals in two areas: academic goals and personal development goals. Academic goals included showing up to school on time daily $(n=3)$, staying on task, and completing assigned work $(n=5)$. Students also mentioned such goals as getting good grades and preparing for re-entry into mainstream high school by staying organized and successfully managing the workload.

Personal development goals were specific to each student $(n=4)$; these included acting as a role model for newer students, accepting redirection and decisions made by CYC practitioners or teachers, being more honest, and developing social skills. Three students identified feeling a sense of responsibility to fulfil their goals because they had become committed to positive personal and academic change.

And I just really wanted to change myself, because I wasn't - like, I'm a sociable kind of guy, people don't think of me as a bad influence on other people or prone, um, to negative influences, or vulnerable to that but, you know, I was. You know, I was doing a lot of bad stuff. You know, skipping school, failing in school, just wasn't working well for me in the family setting. (002jv)

Students informed goal and case plan development by sharing personal or academic goals with primary CYC practitioners $(n=4)$. Other students were more removed from the process and the CYC practitioner then established goal and case plan development to ensure a proper fit with the student $(n=3)$. In one case, development was informed by a parent along with the staff member and student. 
International Journal of Child, Youth and Family Studies (2012) 2 \& 3: 214-233

\section{Student Perspectives on Outcomes, Now and in the Future}

Students spoke of their individual outcomes in three areas: future outcomes not yet achieved, academic outcomes, and socio-emotional outcomes. Socio-emotional outcomes included sub-themes of improved outlook, responsibility, and the development of skills needed for success in the school environment.

Future outcomes. Future outcomes are separate from, but related to, the achievement of program goals. Attending post-secondary education was cited $(n=6)$ as an expected long-term outcome of program participation. Shorter term goals for the future were unique to each individual student and included the completion of specific credits before the end of the school year, taking on a recognized leadership role as a peer helper, developing skills to cope with the academic workload, and feeling comfortable in social situations with peers.

A cademic outcomes. All students $(n=7)$ identified achievement of at least one academic outcome since starting in the program. Most frequently cited was an increase in grade marks $(n=$ 4 ), followed by the ability to complete more school work $(n=3)$, and increased academic success as a result of regular, timely school attendance $(n=2)$.

Then Grade 11, it was just the worst year. That was last year. That was just like the worst year from me. Um, I think I failed - out of eight courses I think I failed six... and she recommended me to this day program... it's been amazing. Like I'm passing everything. Above and beyond my own expectations and goals. Like courses, I got a bonus credit for outstanding achievement in this program, and my work is at academic and university level. (002jv)

Socio-emotional outcomes. Students identified achievement of personal development goals; those who had not identified specific personal development goals were still able to recognize outcomes in this area.

I mproved outlook. Since starting, some students had experienced a change in their world view or feelings about involvement in the program. The following student noted that the content of his personal journals had become more positive and he was able to associate this shift with his positive experience in the program:

Well, at the start of the program I was really dark, I don't want to say it, but sometimes violent... And now, it's like, ah, I used this word before: optimistic, it's more positive than it was... It's very optimistic now. It's got a more positive outlook on life and on change... I was just able to come in here and learn a lot about myself...and about why I'm in this situation... at the beginning it was like, “I'm in here because I'm an idiot", or whatever, but now I'm realizing I'm in here because my past experiences directly influence my school work and my school life. (002jv)

Another student, on the verge of dropping out when she entered the program, experienced a significant shift in the way she thought about education and was looking forward to returning to the program the following year with new aspirations of getting a post-secondary education. 
International Journal of Child, Youth and Family Studies (2012) 2 \& 3: 214-233

This was significant given that she started in the program only a month before the interview took place:

Honestly, before I came to this school it's really, I don't know, never been talked about. But before I came to this school, I wasn't actually going to back to school. I was just going to get a full-time job. But I said that I was going to come here for a month and if I liked it then I would stay.... I thought it was going to be like skipping or whatever, but when I came here I was like, everybody’s smiling, everybody’s like, “hello, good morning, how are you?” And it's like, it makes you feel wanted, like people actually want you to go to school. It's not just my parents like standing over me, "you have to go or else”...but it's like they want you to realize that it's really going to benefit you in the long run. So for the most part it just made me excited; like okay, if I can be excited about school there's something you guys are doing right. And it's like, I think it's the fact that everybody is so upbeat and happy about it; it's like, what makes it worthwhile. (003jv)

Responsibility. Students identified times when they acted responsibly, including acts of reminding themselves of goals and tracking them, determining effective working strategies to stay focused and on task, cooking a meal for everyone in the program, encouraging others to arrive at school on time, approaching staff when an issue presented that they thought would affect school work, and refraining from physical confrontation with peers in times of conflict.

Development of skills needed for success in the school environment. Two students $(n=$ 2) described time management outcomes, indicating that being habitually late for school was no longer an issue for them. Two students noticed an increase in their ability to retain focus on tasks for longer periods than were typical before:

My behaviour is, I'm very, I'm more calm... But now I've actually learned to, like, sink my butt in this chair and actually listen to people. So I couldn't be able to do it four years ago. So yeah, I find that more what you say, I can see now that I'm not fitter, jittery, you know I can actually sit here and talk to you guys. (001)

Students developed social skills and were more confident interacting with peers $(n=3)$. Development of social skills improved students' anger management skills, self-esteem, and selfconcepts. The following student was not yet convinced that he had seen academic or personal success in the program. He spoke of having continued trouble staying on task and not getting "caught up" in distractions created by peers during group sessions. When he did get caught up, a CYC practitioner would initiate discussion about his behaviours following the group session, often offering suggestions for appropriate change. The student indicated that he had become less disruptive and more likely to consider the consequences of an action before engaging in it; however, he spoke with hesitation and was uncertain about whom or what to credit for these changes. Rather, he credited his successes only to developing maturity as a result of growing older. The student noted that he still struggles at times: "Well like, I think things through more before I try to say something. But sometimes it can be hard when a lot of people are joking around about that" $(002 \mathrm{~cm})$.

\section{Relationship}


Descriptions of the process of the development of relationship with CYC practitioners and the labels used by students in naming the relationship give insight into the perceptions of students regarding the relational strategies of CYC practitioners in the setting. The relationship between strategies and outcomes is described through the process of constant engagement by CYC practitioners, which includes passive engagement and persistent engagement. Descriptions and examples of these terms are provided.

Development of the relationship. Relationships with CYC practitioners developed in a variety of ways. Some credited the CYC practitioner for being patient and available to students when they were ready, while others mentioned the reciprocal nature of relationship development (such as shared time during breaks and lunches). Students said that the genuine, personal approach, and sharing of self by the CYC practitioners helped them feel more comfortable and connected in the relationship. Six students $(n=6)$ mentioned that they trusted their primary worker. Half of these $(n=3)$ mentioned that the CYC practitioner was able to facilitate the development of trust through physical presence, caring actions, and consistency.

Naming the relationship. Students used the metaphor of either friend or family to describe their feelings for workers and their perceptions of relationships with them. In one instance, a student differentiated between the relationship he had with his primary CYC practitioner and other CYCs: the first was like family, while the others were more like friends.

I just consider her like my big sister, I can just talk to her about anything. She's always listening and when it's time for class, she'll still have time for me ... She lets me finish what I'm saying and she helps me and she gives me feedback. Yeah, so our relationship is really good. (003cs)

Students identified qualities of the relationship that demonstrated their understanding of its characteristics, even when they chose not to affix a label to it:

I don't know if it's a really close relationship, but we're definitely - she's there, she'll ask how I'm doing, you know. And it just, it's a pretty casual relationship. It's nice though, I feel like I can talk to her and keep in contact with her. There's no - I don't feel there's a barrier usually - between a social worker and a student, which there usually is. (002cs)

R elating strategies to outcomes. Students emphasized that a crucial factor in their experiences of positive relationships and outcomes in the program was the constant engagement of the CYC practitioners. Constant engagement can be expressed passively or persistently depending on whether the CYC practitioner waits for the student to take the initiative that results in action or intervention, or whether the CYC practitioner takes the initiative herself (all CYC practitioners working in the program were female). Students explained how passive engagement, a kind of inactive or background engagement by CYC practitioners in the setting made possible through physical presence, placed the onus on the student to seek out or to propose action or support from the workers. Two essential components of passive engagement allowed students to feel they could initiate action: CYC practitioners’ approachability and availability. Persistent 
International Journal of Child, Youth and Family Studies (2012) 2 \& 3: 214-233

engagement occurred when the CYC practitioner initiated an action or support that was intended to address goals and best interests without having been called upon to do so by the youth.

Passive engagement: Approachability and availability. Students $(n=6)$ felt that the CYC practitioners were approachable and they were comfortable seeking support or advice about academic or personal matters. A student mentioned that he had never forged a positive relationship with a practitioner whom he found unapproachable. He did maintain he found the majority of CYC practitioners to be approachable and this was important in his relationship with them.

Students said that CYC practitioners were available when they needed support, a listening ear, or guidance around an issue. The CYC practitioners made themselves available by being present in the environment, not only during school time but whenever youth and practitioners were together, including before school or during lunch breaks. This availability of the CYC practitioners was a "constant" when the students $(n=3)$ were in the school environment.

I think she just is a very approachable kind of person. She's really down to Earth, so it's really easy to go up to her and say, you know, "I'm having a problem with this so on and so forth, could you help me?” And she doesn’t like, you know, when you're in class we'll talk at break or talk at lunch - she's like, okay. We'll sit down and we'll talk about the issue at hand and maybe brainstorm some ideas as to what we can do and we'll go from there. So she's - she's just been amazing all year. (002jv)

If there is something, if we do have an informal check-in it's usually me who asks her for that...Some weeks are different. Sometimes it could be every day of the week, sometimes it could be twice a week, sometimes it won't be any. It depends on how I'm feeling or what's going on with me. $(003 \mathrm{~cm})$

Passive engagement to solve a bullying problem. Passive engagement is evident in this student's description of how his CYC practitioner took the time with him to address a situation in which he was the target of ongoing bullying. She began by listening to him as he explained the situation, and offered a solution that involved the bullies and the bullied student talking about the situation. The bullied student was able to speak in a safe place where he felt supported by the CYC practitioner. The student later spoke positively about his ability to seek support and to approach the situation in a non-confrontational manner, noting that in the past he would not have approached such a scenario in the same way: “Before I wouldn't be able to do that. I couldn't speak what I had on my mind. It was more done by physical” (001).

Per sistent engagement. Students indicated that the CYC practitioners demonstrated persistence in finding appropriate ways to address issues and reach treatment goals. Although persistent engagement was not always initially welcome, students were able to appreciate their CYC practitioners' use of this strategy in hindsight. The CYCs displayed persistent engagement through ongoing support and motivation $(n=3)$, regular informal check-ins $(n=3)$ and, in one case, routine phone calls to a youth's home or residence. 
Persistent engagement to increase participation. This student was shy and unwilling to participate in the daily group time when he started the program. He would sit in the back of the room or request an early dismissal from school. With persistence and gentle encouragement over time, his primary CYC practitioner helped him to incrementally become more engaged until he was ready to fully participate in the sessions:

Before, she would call me out, like we have this thing called Group where we all, sometimes we all sit and talk. I used to sit in the back and I didn't say anything. Then she would call me out, and before I got really mad, but I realized that it was actually helping me, because I needed that push to talk more....She would tell me - she wouldn't force it on me - she would say "if you can, I just want you to be a part of the group so you can just be a part of it with everybody. You don't have to say anything if you don't want to, but if you do, make sure everyone is quiet so they can hear your opinions.” Yeah, she made me feel really comfortable. $(003 \mathrm{~cm})$

CYC practitioners' constant engagement manifested differently with individual students; they would tailor their degree and method of engagement to the individual and the situation using the different strategies at their disposal. Students appreciated the intentionality they saw in the CYC practitioners' actions when engaging with them to create physical and mental spaces that fostered successful outcomes.

CYC practitioners primarily used persistent engagement with students in their early experiences in the program. These important early experiences provided the foundation for the therapeutic relationship, and helped the students develop an understanding of the role of the CYC practitioners in the program. With this came the students' awareness of the way that CYC practitioners were approachable and available at all times. Thus students recognized their workers' use of passive engagement later in the relationships.

\section{Discussion}

Our research objective was to understand how youth assess the strategies and outcomes of CYC practitioners' interventions in a school-based setting. Overall, the results suggested that students perceived that the CYC practitioners created an environment where they felt motivated and supported in the pursuit of their academic and socio-emotional goals. They understood that their positive outcomes were related to the successful relationships they had been able to develop with the CYC practitioners, and that these relationships stimulated their desire to achieve goals. Students were asked to specifically highlight the practice strategies used by CYC practitioners that were helpful to their success in the program. Given the highly personalized environment described by the students, it is not surprising that results indicated a wide variety of strategies and approaches that had limited identification with EBP/T approaches. The strategies and approaches described by students as being helpful in achieving successful outcomes provide an alternative form of evidence of CYC practitioners' effective working strategies and approaches to practice when compared with residential EBP/Ts.

Our discussion is twofold. First, it focuses on student perceptions of strategies related to the discussion in child and youth care literature on presence, care and belonging, constant 
engagement, friendship, token economies, and "fitting in" at school. Next, it focuses on student perceptions of outcomes related to the literature on young people's future selves and on mentoring relationships between adults and young people. Our intent is to provide a starting point for further dialogue among students, CYC practitioners, and researchers about some of the program and practice strategies significant to young people's outcomes that cannot be assessed or measured in the same ways that EBP/T approaches can.

\section{Youth Perceptions of Program and CYC Practitioners' Practice Strategies}

Presence. For students, the theme of presence was a working strategy of CYC practitioners in the school environment that focused solely on physical presence. The CYC practitioners were there, in the setting. They could be seen and heard and so they were present. The notion of what entails CYC practitioners' presence in the literature reaches beyond the physical. Presence is one of the four themes identified by Krueger (1994) as being fundamental in child and youth care interactions: It goes beyond a CYC practitioner's attendance and includes a state or condition of being attentive and responsive to the moment. Further, it denotes the CYC practitioner's ability to reflect the experiences of young people back to them, and convey the message that "I am here and I will go with you" (Krueger, 2005, p. 26). More than merely physical, Krueger's conception entails mindfulness and action on the part of the CYC practitioner.

Presence is an important factor contributing to a CYC practitioner's constant engagement in the school setting, where he or she is attuned to what is happening and responds when necessary. In further descriptions of the supportive work strategies and constant engagement of the CYC practitioners, the students did mirror features of Krueger's notion of presence. The disconnect seen between the students' concrete perceptions of presence and how it is described more broadly in the literature may be due to differences in the language used and the depth of reflection on the concept of presence. The students have not had the depth of experience that would allow them to conceptualize presence in the way described by Krueger. Further, Krueger's notion of presence is oriented around the physical and mental spaces of the practitioner. The students were not asked to place themselves in the position of the CYC practitioners and understand what presence might look like from their perspective; however, their examples concretely illustrate the ideas that Krueger discusses and thus indicate their importance from a student perspective.

Care and belonging. When students lack a sense of being cared for or belonging in the school setting, they are less likely to see successful outcomes (Lee \& Ryser, 2009). Students identified their experiences with their CYC practitioners as pivotal to their feelings of belonging in the setting. They described factors such as the supportive, family-like atmosphere, and CYC practitioners' use of self to inform practice which contributed to the student's sense of belonging. Feeling a sense of belonging at school was an important factor in the students' abilities to focus on goal achievement and achieve success in the setting. How then did their sense of belonging translate into successful outcomes and positive perceptions of the program? It occurred in a similar way to that of students whose experiences were enhanced through an ethic of caring within school settings. Beginning in relationship and guided by action, an ethic of care uses the concept of caring as the foundation for practice and decision-making. As Waterhouse (2007) 
states, "Defining attributes in this construct are involvement, empathy, holism and individual context. The primary aim of the agent here is to seek to fulfill the needs of others, and as a result, maintain harmony” (p. 30). In previous studies on care in the school setting, care was conceived by young people as:

- feeling welcome in the setting, being acknowledged and understood, feeling respected, getting needed help, and feeling connected by friendship with teachers (Cassidy \& Bates, 2005);

- feeling personally connected to others, feeling like they were in a family-like environment, being encouraged to engage in dialogue, being motivated by adults in the setting (Waterhouse, 2007);

- feeling valued in the setting, receiving personalized attention, and being engaged in the setting in positive ways (Lee \& Ryser, 2009).

Working via an ethic of care, which emphasizes the fostering of a sense of belonging, can be seen as a way to encourage student success. The similarities to our data indicate that the CYC practitioners actively engaged in promoting a culture of care that the students noticed and were affected by. These parallels noted in the literature are not surprising. Child and youth care practice at its core is, after all, based on caring. CYC practitioners are driven by an ethic of care, whether stated or not.

Constant engagement. Constant engagement by CYC practitioners is composed of passive engagement (where the student initiates a request for action) and persistent engagement (where the CYC practitioner initiates action). Consider for a moment constant engagement as a continuum of responsibility and action. At one end, the student holds a high degree of responsibility to act on improving aspects of his or her own life space. The CYC practitioner is present but waits for direction from the student before he or she acts; the CYC practitioner is passively engaged. As we move along the continuum, the degrees of responsibility and action are shared and then transferred to the CYC practitioner. How responsibility and action are shared depends on the situation and the individual. At the other end, it is the CYC practitioner who holds the responsibility to act on improving aspects of the student's life space. The CYC practitioner is present and moves to improve the life space of the student; the CYC practitioner shows persistent engagement.

The concepts of passive and persistent engagement are echoed in a study where young people described how the roles of adults in youth programs helped them to learn strategic thinking (Larson \& Angus, 2011). In the context discussed by Larson and Angus, directive assistance was defined as instances in which adults were the ones who structured the program, "prodding and keeping them focused" (p. 288). Where such strategies were employed, youth developed the skills needed to adhere to deadlines and expectations. Persistent engagement was demonstrated by CYC practitioners as they helped students learn to follow program rules and routines. Facilitative assistance, on the other hand, is seen when the adults refrain from imposing on the work of young people unless they are asked for support (Larson \& Angus, 2011). Adults who use facilitative assistance are involved in behaviour that is similar to passive engagement. They take a step back, allowing young people to engage them when support is required. It is through this non-directive strategy that youth learned strategic thinking skills, where the use of 
higher-order processing and analytical skills helped them accomplish goals. Effective interventions can occur at any point along the continuum of constant engagement; CYC practitioners might use the continuum in determining how best to provide effective interventions and opportunities for experiential learning that continue to support students' learning and development.

Friendship. Without calling workers "friends", the students described their relationships with CYC practitioners as being friend-like. By describing the relationship in this way, the students displayed their awareness of boundaries that were present. They also noted characteristics they thought important in the student-practitioner relationship, indicating an ability on their part to understand that they didn’t have a personal relationship or a friendship with their CYC practitioner.

The move towards professionalization in recent decades has created a shift in the discourse on friendship between practitioners and young people in CYC. Previously, practice values included the notion of friendship between child and youth workers and the young people with whom they were involved; now, the field is more focused on the maintenance of boundaries and professional relationships (Blacker, 2010). In effect "the concept of 'worker as friend' has become increasingly marginalized” (Blacker, 2010, p. 27). The students were aware of and showed respect for an unmentioned, yet concerted, effort on behalf of the CYC practitioners in the setting to refrain from engaging in a "friendship". Students thought carefully about the words they used to describe their relationships with CYC practitioners, and refrained from affixing a label of friendship to their descriptions. Instead, students focused mainly on the helping nature of the relationships in which they were engaged. The language - CYC practitioners being friendlike or family-like - denotes a need for the students to use examples of their own relational experiences as comparisons to confidently and effectively describe their relationships with CYC practitioners.

Token economy. The students in this study spoke highly of the token economy embedded into the program strategy, indicating that the possibility of reward motivated them to be on time, be prepared for classes, and notice and act on opportunities to help others. Token economies and similar strategies are widely used in group treatment settings (Gharabaghi \& Phelan, 2011; VanderVen 2009), though their use in CYC practice is the focus of ongoing debate in the literature. VanderVen $(1995,1999,2005)$ is a prominent voice on the flaws that exist in point and level systems in the literature. Instead of encouraging students to act with an internal sense of responsibility or purpose, she posits that a token economy acts as an external locus of control whereby students are motivated to action by the possibility of reward (VanderVen, 1999). In our study, students liked the token economy precisely because of the rewards; while the intervention encouraged responsible actions, the students may have been engaging in such actions as a means to an end. They indicated they were more focused on getting the "stuff" than they were on gaining recognition for their actions.

Token economies can also be seen as control-based, where it is the one with control - the CYC practitioner - who determines eligibility for rewards and awards tokens to the student (Gharabaghi \& Phelan, 2011). Students didn’t acknowledge this power differential that existed in the token economy. It could be that they didn't care, or that the rewards in the setting were more attractive than their need for empowerment, or even that they hadn't taken the time to question 
the complexities of token economies. Is a control-based system the best way to promote the development of pro-social, responsible behaviours? Surely not, but students did speak of having a sense of responsibility in the fulfillment of their goals, indicating that some aspect of the overall program or the manner in which the staff interacted with students allowed for the development of a sense of responsibility. Further, with the token economy comes the opportunity for students to have control by offering choices. As a program strategy, the token economy was not optional; all students participated. Choices existed within the structure of the program; students decided how much time and effort they wanted to invest in collecting “dollars”. They could also choose how and when to spend their saved dollars at auction time.

“Fitting in" at school. The students who were interviewed attended the program because for some reason they had difficulty performing in a mainstream high school setting. Benefits of participation in the program were twofold: They received required academic support and they learned socio-emotional skills (e.g., time management, focus on tasks, social skills) that would allow them to "fit in", (or reintegrate) to the mainstream high school system for graduation. Students noted that the CYC practitioners helped them develop these skills.

How are CYC practitioners able to encourage the development of the skills that are needed for success in the school environment? "Fitting in" at school requires that students are able to follow rules and abide by expectations that exist in the school environment. According to Hewitt (1998), the development of skills that are needed for success in the school environment must begin by nurturing of a sense of belonging in students. Adults in the setting can foster a sense of belonging by refraining from judging student behaviours or imposing personal or organizational values, and by providing them with alternatives when behaviours are not aligned with the norms of the setting (Hewitt, 1998). CYC practitioners were able to do this by working via the ethic of care described previously. Given their constant engagement with students, CYC practitioners were in a position to recognize and promote pro-social behaviours important to help students develop skills associated with successful integration.

\section{Youth Perceptions of Outcomes}

Outcomes: Future goals, future selves. The students' prominent future goal was to attend post-secondary education. In another study where occupational attainment was the primary focus, attainment of post-secondary education was one of the categories that emerged when youth participated in a "possible selves" mapping interview with 11- to 13-year-olds (Shepard \& Marshall, 1999). In our study, students’ ages and the educational context of the setting may have been influential factors that led them to place more emphasis on educated selves rather than occupational selves as was the case with the participants in Shepard and Marshall's (1999) study.

Mentoring relationships: Different players, similar outcomes. Rhodes, Spencer, Keller, Liang, and Noam (2006) describe how close mentoring relationships between adults and youth influence youth through three interrelated processes: facilitated social-emotional development, cognitive development, and the promotion of positive development of self-identity. Students reported that CYC practitioners assisted the achievement of outcomes in all of these 
areas, indicating that similar processes are involved in the supporting of youth across different settings.

In this study, students likened their relationships with their CYC practitioners to family and friends - relationships that are presumed to be close and supportive. The associations of their workers with family indicate that the students' relationships with the CYC practitioners meet their emotional needs and thus promote development in this area. Rhodes (2004) suggests that the ability to foster close connections with non-parental adults is an important indicator of positive socio-developmental outcomes, and staff can act as secondary attachment figures for the young people with whom they engage. Similarly, at-risk youth in another study who experienced caring relationships with educators also used a family parallel in their descriptions of their relationships (Waterhouse, 2007).

Formal and informal conversations and small talk feature prominently in students’ descriptions of the working strategies of the CYC practitioners. Constant engagement, assessments and case planning, and at some point virtually all other working strategies require the presence of dialogue. In addition to being a necessary ingredient of working strategies, cognitive development is facilitated with conversation in mentoring relationships (Rhodes, 2004). This is not surprising since it is conversation that is the "bedrock on which youth work is built" (Young, 2006, p. 85); relationships are generated and evolve through conversation and intervention plans are the result of these conversational interactions. Conversation is also a theme in Waterhouse's (2007) study, where students described that the family-like environment encouraged rich dialogue that in turn invited sharing and facilitated problem solving. Further, dialogue is a necessary ingredient in the development of critical thinking and reflection skills for young people (Young, 2006).

CYC practitioners promote the development of self-identity in students through their constant engagement in the setting and the program. With group and individual conversations and interventions, practitioners promote the heightening of self-awareness and show the students new and alternative choices. Individually, this is seen when students help to plan and assess the strategies used in the process of goal attainment; in group interactions, students develop social and life skills through activity, reflection, and discussion led by the CYC practitioners. The way that students described their outcomes bears evidence to the importance of the establishment of relationship as the basis for progress toward the achievement of goals. As the literature suggests, young people succeed best when they are able to form and maintain relationships that support their needs and provide ample room for growth and development. It was made clear by the students in this study that they considered the relationship they developed with their CYC practitioner to be a necessary basis for the achievement of successful outcomes.

Most of the strategies that are identified by students as contributing factors to their successful outcomes are ones that defy placement in the realm of EBP/T, yet the literature provides significant conceptual support for the importance of most of these strategies. While this represents only a small sample of the perceptions of young people about the work of their CYC practitioners, it provides an important window of insight into those factors that are difficult to assess scientifically and systematically.

\section{References}


International Journal of Child, Youth and Family Studies (2012) 2 \& 3: 214-233

Blacker, H. (2010). Relationships, friendship and youth work. In T. Jeffs \& M. K. Smith (Eds.), Youth work practice (pp. 15-30). New York: Palgrave Macmillan.

Cassidy, W., \& Bates, A. (2005). “Drop-outs” and "push-outs”: Finding hope at a school that actualizes the ethic of care. American Journal of Education, 112(1), 66-102.

Gharabaghi, K., \& Phelan, J. (2011). Beyond control: Staff perceptions of accountability for children and youth in residential group care. Residential Treatment for Children \& Youth, 28(1), 75-90. DOI:10.1080/0886571X.2011.550172

Hewitt, M. B. (1998). Helping students feel like they belong. Reclaiming Children and Youth, 7(3), 155-160.

Krueger, M. (1994). Framing child and youth care in moments of rhythm, presence, meaning and atmosphere. Child and Youth Care F orum, 23(4), 223-229.

Krueger, M. (2005). Four themes in youth work practice. Journal of Community Psychology, 33(1), 21-29. DOI: 10.1002/jocp.20033

Larson, R. W., \& Angus, R. A. (2011). Adolescents' development of skills for agency in youth programs: Learning to think strategically. Child Development, 82(1), 277-294.

Lee, K., \& Ryser, G. (2009). Illuminating adolescent voices: Identifying high school students’ perceptions of teacher caring. Academic Leadership: The Online Journal, 7(4).

Rhodes, J. E. (2004). The critical ingredient: Caring youth-staff relationships in after-school settings. New Directions for Youth Development, 101, 145-161.

Rhodes, J. E., Spencer, R., Keller, T. E., Liang, B., \& Noam, G. (2006). A model for the influence of mentoring relationships on youth development. Journal of Community Psychology, 34(6), 691-707. DOI: 10.1002/jcop.20124

Shepard, B., \& Marshall, A. (1999). Possible selves mapping: Life-career exploration with young adolescents. Canadian Journal of Counselling, 33(1), 37-54.

Stuart, C., Fulton, R., Kroll, T., Rapuano, J., \& McMillan, C. (2008). Child and youth care practitioner s contributions to evidence-based practice in group care. Retrieved from Ryerson University Digital Commons: http://digitalcommons.ryerson.ca/cyc/1

VanderVen, K. (1995). "Point and level systems": Another way to fail children and youth. Child \& Youth Care Forum, 24(6), 345-367.

VanderVen, K. (1999, April). The case against point systems and grading in behaviour programs. CYC-OnLine, Issue 3. Retrieved from http://www.cyc-net.org/cyc-online/cycol-0499-karen.html 
International Journal of Child, Youth and Family Studies (2012) 2 \& 3: 214-233

VanderVen, K. (2009). Why focusing on control backfires: A systems perspective. Reclaiming Children and Youth, 17(4), 8-13.

Waterhouse, T. A. (2007). Giving voice: Exploring the school-based care experiences of at-risk youth (Doctoral dissertation, Simon Fraser University). Available from Dissertations \& Theses: Full Text (Publication No. AAT NR41032).

Young, K. (2006). The art of youth work. Dorset, UK: Russell House Publishing. 